\title{
Effect of One Year of Cryopreservation on the Activity of Lysosomal Hydrolases from EBV-Transformed Lymphocytes
}

\author{
A. S. de Mello, ${ }^{1}$ F. B. Mendes, ${ }^{1}$ K. Michelin-Tireli, ${ }^{2}$ M. V. Camelier, ${ }^{2}$ and J. C. Coelho' \\ ${ }^{1}$ Postgraduate Program in Biological Sciences and Biochemistry, Department of Biochemistry, Federal University of Rio Grande do Sul, \\ 90035-003 Porto Alegre, RS, Brazil \\ ${ }^{2}$ Medical Genetics Service, Clinical Hospital of Porto Alegre, 90035-003 Porto Alegre, RS, Brazil
}

Correspondence should be addressed to A. S. de Mello, melloas@gmail.com

Received 25 November 2010; Revised 15 March 2011; Accepted 23 March 2011

Academic Editor: Ayman El-Kadi

Copyright (C) 2011 A. S. de Mello et al. This is an open access article distributed under the Creative Commons Attribution License, which permits unrestricted use, distribution, and reproduction in any medium, provided the original work is properly cited.

\begin{abstract}
Background. The Epstein-Barr virus (EBV) was used as an agent of B lymphocyte proliferation for subsequent diagnosis of lysosomal storage disease. Due to the constant handling of long-preserved samples in our cell bank, we decided to observe the behavior and then compare cultured and frozen samples for at least one year's cryopreservation. Methods. Twenty-five samples from healthy individuals were used to assess the possible changes in activity of enzymes $\beta$-galactosidase, $\beta$-glucosidase, $\alpha$ iduronidase, $\alpha$-galactosidase, and $\alpha$-glucosidase. Transmission electron microscopy was used to confirm cell transformation of B lymphocytes into EBV-infected cells, generating lymphoblastoid cell lines. Results. Transmission electron microscopy findings confirmed previous reports in the literature that is, significant and evident morphological changes in the nucleus occur after day 12 and the consequent cell transformation into EBV-infected cells. After thawing and subsequent treatment with the five enzymes utilized, we observed no significant changes in samples cryopreserved for more than one year, as compared to samples cultured for 12 days.
\end{abstract}

\section{Introduction}

Inborn errors of metabolism (IEM) is the term used to refer to a set of genetically determined autosomal recessive diseases that include around 500 different dysfunctions and that account for $10 \%$ of genetic diseases. IEM have been divided into groups, according to the repercussions to cells and to the associated metabolic defect [1]. One of these groups of diseases includes lysosomal storage diseases (LSD), in which abnormal amounts of built-up substrates are stored in cells, usually leading to changes in cell architecture and function. These dysfunctions are generally caused by a deficiency in specific enzymes, among which $\beta$-galactosidase, $\beta$-glucosidase, $\alpha$-iduronidase, $\alpha$-galactosidase, and $\alpha$-glucosidase, whose deficit may cause GM1-gangliosidosis, Gaucher, muccopolysaccharidosis type 1, and Fabry and Pompe diseases, respectively.

It is believed that early treatment may lessen the chances of irreversible damage like hepatomegaly and/or splenomegaly, skeletal changes, and significant alterations in the central nervous system [2]. Physicians establish a preliminary diagnosis based on clinical features. This initial diagnosis is then confirmed by laboratory analysis, which is usually performed using leukocytes, though fibroblasts and whole blood (blood spots) may also be used, and, in some conditions, plasma or urine. However, these biological specimens degenerate with time, compromising the enzyme test or its repetition [3].

When it is necessary to store cells for longer periods for enzyme activity analysis, cultivated fibroblasts are used, though these have limited lifespan, and suffer the effects of aging and modifications of enzyme activities during senescence $[3,4]$. Moreover, the discomfort as the collection, the lack of specific knowledge as to the correct collection procedure observed in some laboratories, and the even greater trouble in recollecting material are negative aspects of the utilization of fibroblasts obtained from skin fragments. In this scenario, the technique is used by the few professionals who are virtually acquainted with the standard procedures of this important diagnosis tool [5]. 
Alternatively, lymphoblastoid cell lines (LCLs) obtained from lymphocytes B in the peripheral blood flow incubated with the Epstein-Barr virus (EBV) may be used. In comparison with the skin fibroblast lines, this technique offers a few advantages: (a) faster collection of material, (b) lower cytogenetic variation, (c) faster cell proliferation with no senescence, (d) growth in suspension, (e) massive cell material proliferation, (f) freezing and subsequent reestablishment of cultures with higher success rates as compared to fibroblasts, (g) low volumes ( 2 to $3 \mathrm{~mL}$, or less) of peripheral blood required, and (h) stability of the karyotype and of phenotypical expression $[3,6-8]$.

The EBV belongs to the Herpesviridae family and is the etiological agent of infectious mononucleosis [9], among other diseases such as Burkitt lymphoma, Hodgin's disease, and T-cell lymphoma [10]. Similarly to some LSD cells, EBVtransformed lymphocytes likewise form significant cytoplasm vacuoles caused by immune response [6].

Our research group has shown that no significant changes in enzyme activities are observed, before and after LSD freezing, within a 180-day cryopreservation period [11]. In addition to the shorter culture time (12 days), the maintenance of activities along time would guarantee the subsequent repetition of the procedure, if necessary.

The present study evaluates the activity of the five lysosomal hydrolases mentioned above after a 1-year cryopreservation period and tested the efficiency of the LCL transformation method [12] using transmission electron microscopy (TEM).

\section{Materials and Methods}

2.1. Blood Collection. Twenty milliliter peripheral blood samples were collected from 25 healthy individuals using heparinized tubes for subsequent culture of peripheral blood mononuclear cells (PBMCs). These cells were obtained by Fycoll-Histopaque (Sigma, St. Louis, Mo, USA) gradient centrifugation. The protocol was approved by both scientific and ethics committees (Clinical Hospital of Porto Alegre, HCPA, Porto Alegre, Brazil), and written informed consent was obtained from all subjects.

\subsection{Preparation and Conservation of EBV B95'8 Cells. EBV} B- 95 ' 8 cells were acquired from the Cell Bank of the State of Rio de Janeiro, from the Federal University of the State of Rio de Janeiro, and frozen in liquid nitrogen upon use. These cells were then cultured to the required volume in RPMI1640 medium supplemented with $20 \%$ fetal calf serum and exposed to a $\mathrm{CO}_{2}$-free atmosphere by closing the culture flask for 5 to 7 days. Next, adherent cells were detached using Cell Scraper (Corning, New York, NY, USA) and then filtered in a $0.22-\mu \mathrm{m}$ filter (Millipore, Bedford, Mass, USA).

2.3. Mononuclear Cell Culture. After separation of PBMCs, cells were counted in a Neubauer chamber and adjusted to $9 \times 10^{6}$ cells per culture flask. Next, $2 \mu \mathrm{g} / \mathrm{mL}$ cyclosporine A (CyA) (Sandimmum, Sandoz, East Hannover, NJ, USA) and $1 \mathrm{~mL}$ of the viral particle were added. The viral particle was obtained using the EBV B-95'8 strain. The RPMI1640 medium was replaced after 4 and after 8 days, with CyA $1 \mu \mathrm{g} / \mathrm{mL}$ supplementation. On day 12 , cultures were centrifuged $(400 \times \mathrm{g}, 10 \mathrm{~min})$ in PBS medium, after which cells were collected. Then, half of the collected cells were submitted to measurement of enzyme activity and half was cryopreserved for one year.

2.4. Freezing and Thawing of Samples. Cells were gradually frozen in fetal bovine serum supplemented with 10\% DMSO in a freezing container immersed in isopropanol (Nalgene Nunc Int., Rochester, NY, USA). Samples were kept in the freezer at $-80^{\circ} \mathrm{C}$ for $24 \mathrm{~h}$ and then conserved in liquid nitrogen upon enzyme activity evaluation.

2.5. Electron Microscopy. After the separation of the mononuclear fraction by Fycoll-Histopaque (Sigma, St. Louis, Mo, USA) gradient centrifugation, cells were grouped as lymphocytes and EBV-infected lymphocytes. Pellet cells of the peripheral blood were fixed in a mixture formed by paraformaldehyde $4 \%$ and glutaraldehyde $2.5 \%$ buffered with $0.1 \mathrm{M}$ phosphate $(\mathrm{pH} 7.3$ ) at room temperature and postfixed in phosphate-buffered $\mathrm{OsO}_{4}$, dehydrated in ascending alcohol and acetone, and embedded in araldite (Durcupan ACM, Fluka). Ultrathin sections $(70 \mathrm{~nm})$ were stained with $2 \%$ uranyl acetate followed by lead citrate and examined under JEM 1200 EX II (CME -UFRGS).

2.6. Assessment of Lysosomal Acid Hydrolases. Analyses of human lysosomal acid hydrolases were performed in lymphocytes and LCLs on the 12th day of culture and after 365 days of freezing. $\beta$-glucosidase activity was evaluated using a well-established method [13], which utilizes 4-methylumbelliferyl- $\beta$-D-glucoside (Sigma) as synthetic substrate, together with sodium taurocholate (Sigma), under standard conditions ( $\mathrm{pH} 5.5$ and $37^{\circ} \mathrm{C}$ ). Activities of enzymes $\beta$-galactosidase [3] and $\alpha$-iduronidase [14] were estimated by incubation with 4 -methylumbelliferyl- $\beta$-D-galactoside (Sigma) and 4-methylumbelliferyl- $\alpha$-L-iduronide (Sigma) as substrates, respectively, under standard conditions $(\mathrm{pH} 4.0$ and $\mathrm{pH} 2.8$, resp., at $37^{\circ} \mathrm{C}$ ). Furthermore, $\alpha$-galactosidase activity was evaluated according to another classical method [15], which uses 4 -methylumbelliferyl- $\alpha$-D-galactoside (Sigma) as synthetic substrate together with citrate phosphate (Sigma), under standard conditions ( $\mathrm{pH} 4.8$ and $37^{\circ} \mathrm{C}$ ). Activity of the enzyme $\alpha$-glucosidase was evaluated according to again another method [16], which uses 4-methylumbelliferyl- $\alpha$-Dglucoside (Sigma) as the synthetic substrate, together with acetate (Sigma) in standard conditions ( $\mathrm{pH} 4.0$ and $\left.37^{\circ} \mathrm{C}\right)$. Fluorescence was evaluated by spectrofluorometry $(365 \mathrm{~nm}$ excitation and $450 \mathrm{~nm}$ emission). Data are expressed as $\mathrm{nmol} / \mathrm{h} / \mathrm{mg}$ of protein [17].

2.7. Statistical Analysis. Data were reported as mean \pm SD. The activities of the five enzymes evaluated on day 12 in culture and immediately on day 325 in freezing were compared using the Student's $t$-test $(P<.05)$ in the software GraphPad Prism 5. 


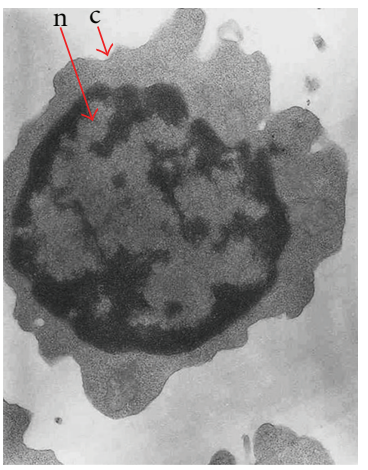

(a)

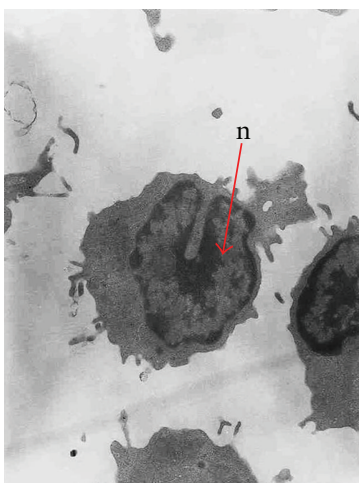

(c)

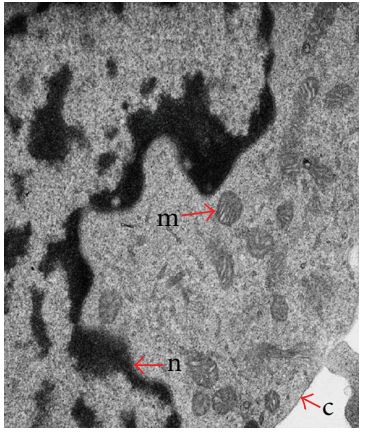

(e)

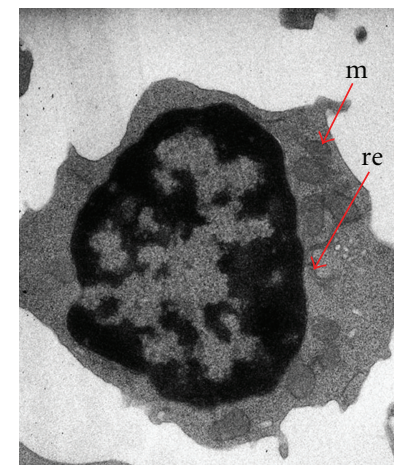

(b)

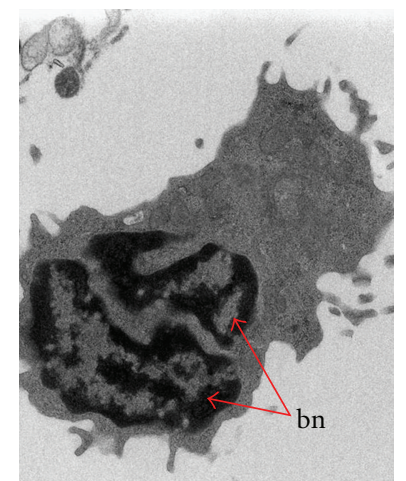

(d)

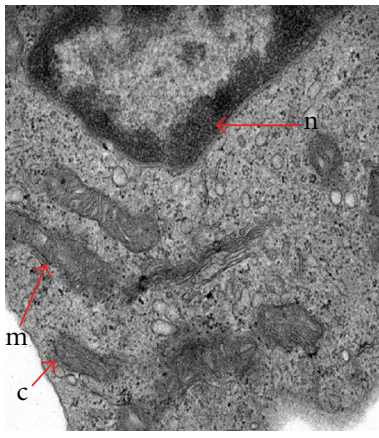

(f)
FIGURE 1: Evaluation of LCL's transformation by electron microscopy: (a) $(0.5 \mu \mathrm{m})$, (b) $(0.5 \mu \mathrm{m})$, (e) $(1 \mu \mathrm{m})$-Lymphocytes before transformation. (c) $(300 \mathrm{~nm})$, (d) $(300 \mathrm{~nm}),(\mathrm{f})(1 \mu \mathrm{m})-$ Lymphocytes after transformation. Bn: binucleation, c: cytoplasm, $\mathrm{m}$ : mitochondria, n: nucleus, re: endoplasmic reticulum.

\section{Results}

3.1. Evaluation of Cell Transformation. Cell transformation was successful in $100 \%$ of cases, since the material collected from all 25 subjects was successfully transformed.

Figures 1(a), 1(b), and 1(e) show that lymphocytes presented a morphologically well-defined nucleus, with preserved mitochondria. Also, endoplasm reticuli, ribosomes, and Golgi apparatus were well organized in the cytoplasm. Figures 1(c), 1(d), and 1(f) from lymphocytes cultured with EBV show a higher number of cell organelles, apart from significant morphological changes such as larger mitochondrial

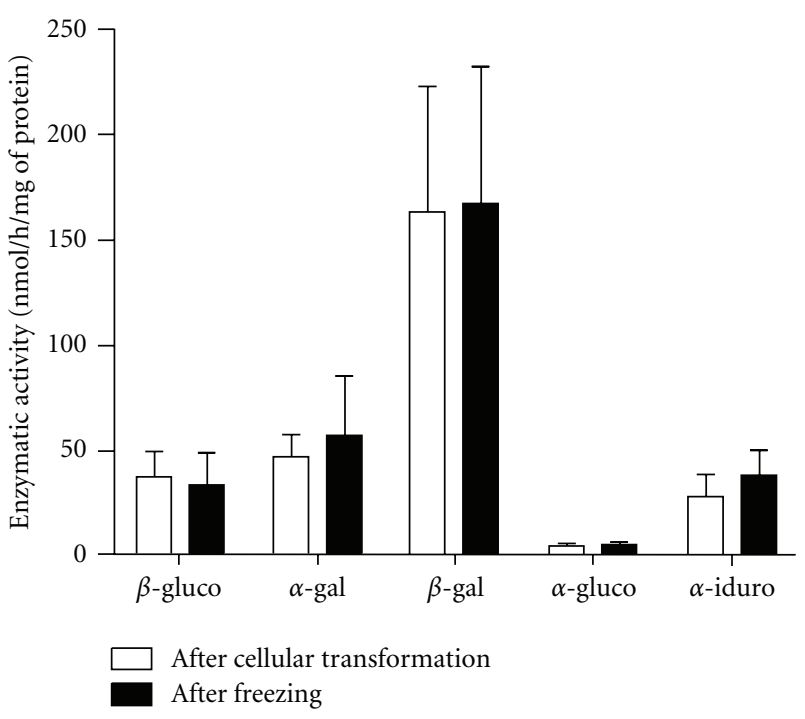

FIGURE 2: Enzymatic analysis of acid hydrolases from LCLs. Data are expressed as mean \pm standard deviation. $\beta$-gluco: $\beta$-glucosidase, $\alpha$ gal: $\alpha$-galactosidase, $\beta$-gal: $\beta$-galactosidase, $\alpha$-gluco: $\alpha$-glucosidase, and $\alpha$-iduro: $\alpha$-iduronidase.

having disorganized cristae, electrolucid structures (filled with material), numerous lysosomes, binucleated cells, and myelin bodies. These features confirm the transformation of lymphocytes by the EBV.

3.2. Assessment of Lysosomal Acid Hydrolases. No statistically significant changes were observed between the results obtained for both times (Figure 2). After the 1-year cryopreservation period of samples, $\alpha$-galactosidase activity was similar to that measured on day 12 of culture $(55.9 \pm 29.6$ and $46.4 \pm 11.5$, resp.). The same was observed for the other enzymes: $\beta$-glucosidase $(31.7 \pm 17.5$ and $35.8 \pm 13.8$, resp.), $\beta$-galactosidase $(166.4 \pm 68.7$ and $163.7 \pm 60.9)$, $\alpha$-glucosidase $(5.1 \pm 2.7$ and $4.4 \pm 1.9$, resp. $)$, and $\alpha$ iduronidase $(33.1 \pm 16.2$ and $27.6 \pm 10.3$, resp.).

\section{Discussion}

Two previous studies conducted by our research group have demonstrated the effectiveness of this protocol in culturing lymphocytes transformed with EBV in a short period of time (12 days) [11, 18]. Since the culturing of transformed lymphocytes is less labor intensive and the material (blood) is more easily obtained-as compared to fibroblasts [3], we decided to further investigate the influence of lymphocyte cryopreservation times on the activity of lysosomal hydrolases and to evaluate the efficiency of the transformation of these cells using the EBV.

In the present study, we evaluated five enzymes largely employed in the diagnosis of LSDs of common occurrence. According to Staretz-Chacham et al. [19], the methods used in our study are sensitive and selective for the measurement of these enzymes activities in the diagnosis of LSDs. The activity of all enzymes remained essentially constant after 
the 1-year cryopreservation period. This indicates that these samples may be safely handled after this period of time. Since blood collection is a less invasive approach as compared to skin biopsy, such result shows great promise. The consistency in enzyme activities has been demonstrated in 30- and 6month cryopreservation periods $[11,18]$.

Cell culture was followed up throughout the cell culture period by observing the formation of clusters, which are, according to the literature, clear indicators of cell transformation [20]. These clusters increased with time, upon becoming visible to the naked eye.

Transmission electron microscopy afforded to detect myelinoid bodies, binucleated cells, nuclear invagination, and cytoplasm vacuoles in EBV-infected cell cultures (Figure 1). These findings confirm the successful transformation of lymphocytes by the EBV. This transformation, side by side with the fact that enzyme activities remained stable after the 1-year cryopreservation period cells were submitted to, affords an excellent approach to diagnose LSDs.

The presence of myelinoid bodies after the transformation of cells by the EBV has been observed in some LSDs, as reported in the literature [21-23]. This was also seen in normal cells in the present study. Disorders like NiemannPick type $b$ and $c[7,21]$ were also characterized by the formation of these myelin bodies in lymphocytes.

Lymphocyte binucleation (Figure 1(d)) has been reported in studies using lymphocytes of myeloma patients [24]. In our study, the cell cultures transformed by EBV B-95' 8 strain originated from EBV-infected lymphocytes also exhibited the phenomenon.

The results obtained in the present study are in agreement with the findings obtained by our research group in previous studies $[11,18]$. This means that the freezing of samples according to a less invasive method which affords the easy obtainment of material allows to conduct a reliable enzyme analysis even when the sample is frozen for a long period of time.

\section{Acknowledgments}

The authors are grateful to GPPG-HCPA, CAPES, and CNPq for financial support, to HCPA Blood Bank (Clarisse A. Juckowsky, M.D. and Sandra R. C. Machado), and to UFRGS Center for Electron Microscopy (Moema Q. Vieira).

\section{References}

[1] L. Sinclair, "A new look at the inborn errors of metabolism," Annals of Clinical Biochemistry, vol. 19, no. 4, pp. 314-321, 1982.

[2] D. A. Wenger, S. Coppola, and S. L. Liu, "Insights into the diagnosis and treatment of lysosomal storage diseases," Archives of Neurology, vol. 60, no. 3, pp. 322-328, 2003.

[3] R. Minami, Y. Watanabe, and T. Kudoh, "Lysosomal acid hydrolases in established lymphoblastoid cell lines, transformed by Epstein-Barr virus, from patients with genetic lysosomal storage diseases," Human Genetics, vol. 44, no. 1, pp. 79-87, 1978.

[4] J. Elliott, M. B. Coulter-Mackie, J. H. Jung, D. I. Rodenhiser, and S. M. Singh, "A method for transforming lymphocytes from very small blood volumes suitable for paediatric samples," Human Genetics, vol. 86, no. 6, pp. 615-616, 1991.

[5] A. S. Sun, B. B. Aggarwal, and L. Packer, "Enzyme levels of normal human cells: aging in culture," Archives of Biochemistry and Biophysics, vol. 170, no. 1, pp. 1-11, 1975.

[6] T. Levade, A. Maret, and R. Salvayre, "Biochemical and ultrastructural studies on an Epstein-Barr virus-transformed lymphoid cell line from a Niemann-Pick disease type C patient," Biochimica et Biophysica Acta, vol. 877, no. 3, pp. 415422, 1986.

[7] R. Minami, M. Suzuki, and T. Kudoh, “ $\alpha$ L iduronidase activity in established lymphoblastoid cells from patients with Hurler and Scheie syndromes transformed by Epstein Barr virus," Tohoku Journal of Experimental Medicine, vol. 122, pp. 393396, 1977.

[8] A. Negre, R. Salvayre, and A. Maret, "Lymphoid cell lines as a model system for the study of Wolman's disease: enzymatic, metabolic and ultrastructural investigations," Journal of Inherited Metabolic Disease, vol. 9, no. 2, pp. 193-201, 1986.

[9] J. C. Niederman, R. W. McCollum, G. Henle, and W. Henle, "Infectious mononucleosis. Clinical manifestations in relation to EB virus antibodies," Journal of the American Medical Association, vol. 203, no. 3, pp. 205-209, 1968.

[10] T. Takahashi, T. Kawabe, Y. Okazaki et al., "In vitro establishment of tumorigenic human B-lymphoblastoid cell lines transformed by Epstein-Barr virus," DNA and Cell Biology, vol. 22, no. 11, pp. 727-735, 2003.

[11] A. S. De Mello, F. Provin, K. Michelin-Tireli, M. V. Camelier, and J. C. Coelho, "Feasibility of using cryopreserved lymphoblastoid cells to diagnose some lysosomal storage diseases," Cell Proliferation, vol. 43, no. 2, pp. 164-169, 2010.

[12] M. Sugimoto, Y. Furuichi, T. Ide, and M. Goto, "Incorrect use of "immortalization" for B-lymphoblastoid cell lines transformed by Epstein-Barr virus," Journal of Virology, vol. 73, no. 11, pp. 9690-9691, 1999.

[13] S. P. Peters, P. Coyl, and R. H. Glew, "Differentiation of $\beta$ glucocerebrosidase from $\beta$ glucosidase in human tissues using sodium taurocholate," Archives of Biochemistry and Biophysics, vol. 175, no. 2, pp. 569-582, 1976.

[14] J. J. Hopwood, V. Muller, A. Smithson, and N. Bagget, "A fluorometric assay using 4-methylumbelliferyl $\alpha$-L-iduronide for the estimation of $\alpha$-L-iduronidase activity and the detection of Hurler and Scheie syndromes," Clinica Chimica Acta, vol. 92, no. 2, pp. 257-265, 1979.

[15] R. J. Desnick, K. Y. Allen, S. J. Desnick, M. K. Raman, R. W. Bernlohr, and W. Krivit, "Fabry's disease: enzymatic diagnosis of hemizygotes and heterozygotes. $\alpha$-galactosidase activities in plasma, serum, urine, and leukocytes," The Journal of Laboratory and Clinical Medicine, vol. 81, no. 2, pp. 157-171, 1973.

[16] Y. Li, C. R. Scott, N. A. Chamoles et al., "Direct multiplex assay of lysosomal enzymes in dried blood spots for newborn screening," Clinical Chemistry, vol. 50, no. 10, pp. 1785-1796, 2004.

[17] O. H. Lowry, N. J. Rosebrough, A. L. Farr, and R. J. Randall, "Protein measurement with the Folin phenol reagent," The Journal of biological chemistry, vol. 193, no. 1, pp. 265-275, 1951.

[18] A. S. Mello, M. G. Burin, K. Michellin et al., "Epstein-Barr virus-induced transformation of $\mathrm{B}$ cells for the diagnosis of genetic metabolic disorders-enumerative conditions for cryopreservation," Cell Proliferation, vol. 39, no. 1, pp. 29-36, 2006. 
[19] O. Staretz-Chacham, T. C. Lang, M. E. Lamarca, D. Krasnewich, and E. Sidransky, "Lysosomal storage disorders in the newborn," Pediatrics, vol. 123, no. 4, pp. 1191-1207, 2009.

[20] H. M. Oh, J. M. Oh, S. C. Choi et al., "An efficient method for the rapid establishment of Epstein-Barr virus immortalization of human B lymphocytes," Cell Proliferation, vol. 36, no. 4, pp. 191-197, 2003.

[21] J. C. Bes, R. Salvayre, and T. Levade, "Ultrastructural investigations on two lymphoid cell lines from Niemann-Pick disease type B," Biology of the Cell, vol. 50, no. 3, pp. 299-302, 1984.

[22] A. Maret, R. Salvayre, and A. Negre, "Epstein-Barr virus transformed lymphoid cell lines as a new model system in culture for the study of GM2-gangliosidoses: tay-Sachs and Sandhoff diseases," Biology of the Cell, vol. 53, no. 3, pp. 293296, 1985.

[23] A. Maret, R. Salvayre, N. Livni, J. Icart, M. Vuillaume, and L. Douste-Blazy, "Biochemical and ultrastructural findings in Epstein-Barr virus-transformed lymphoid cell lines from type 1 Gaucher disease," Biology of the Cell, vol. 59, no. 1, pp. 101104, 1987.

[24] D. Catovsky, P. J. Holt, and D. A. Galton, "Binucleated blastcells in lymphocyte cultures from myelomatosis," Immunology, vol. 22, no. 6, pp. 1103-1109, 1972. 

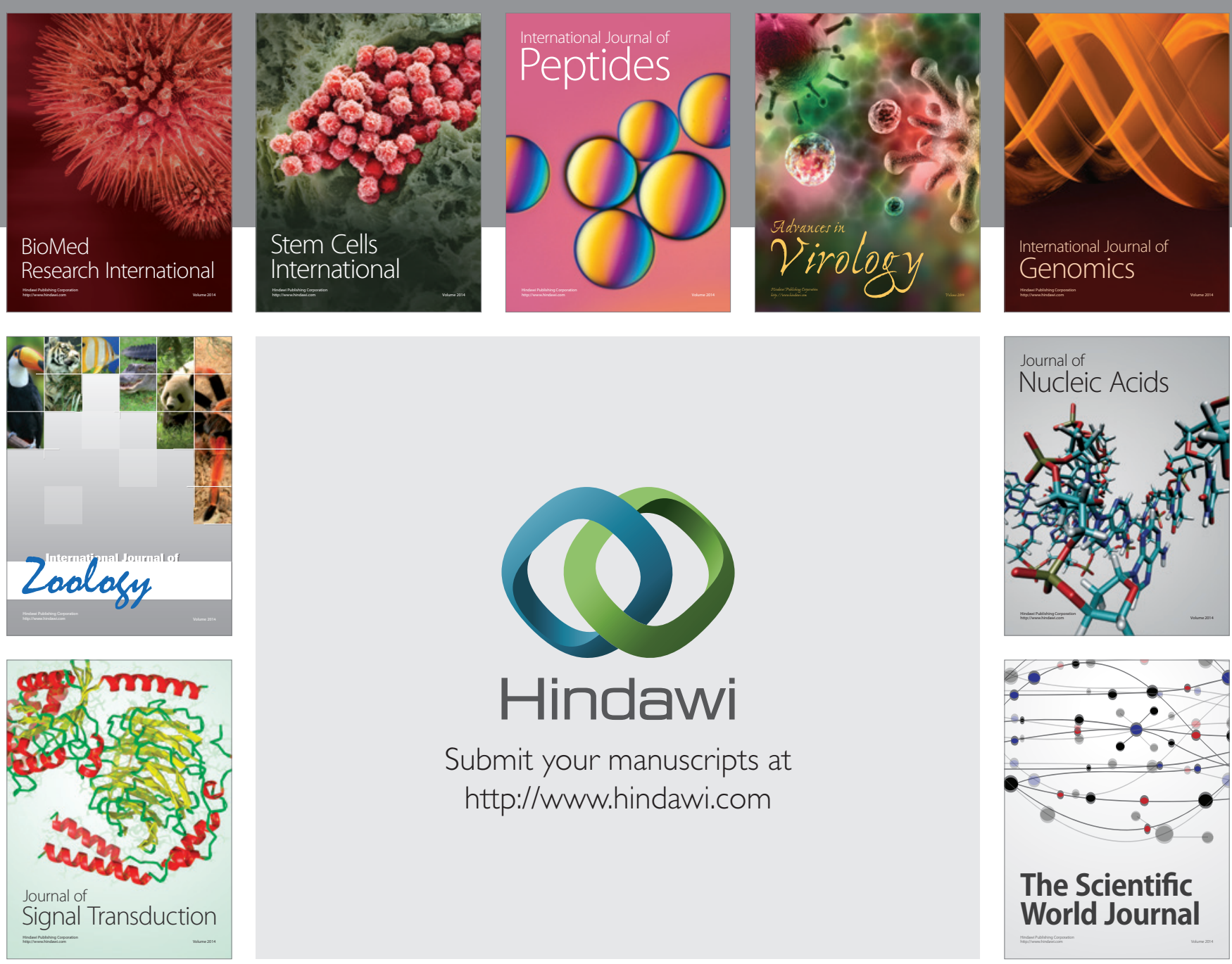

Submit your manuscripts at

http://www.hindawi.com
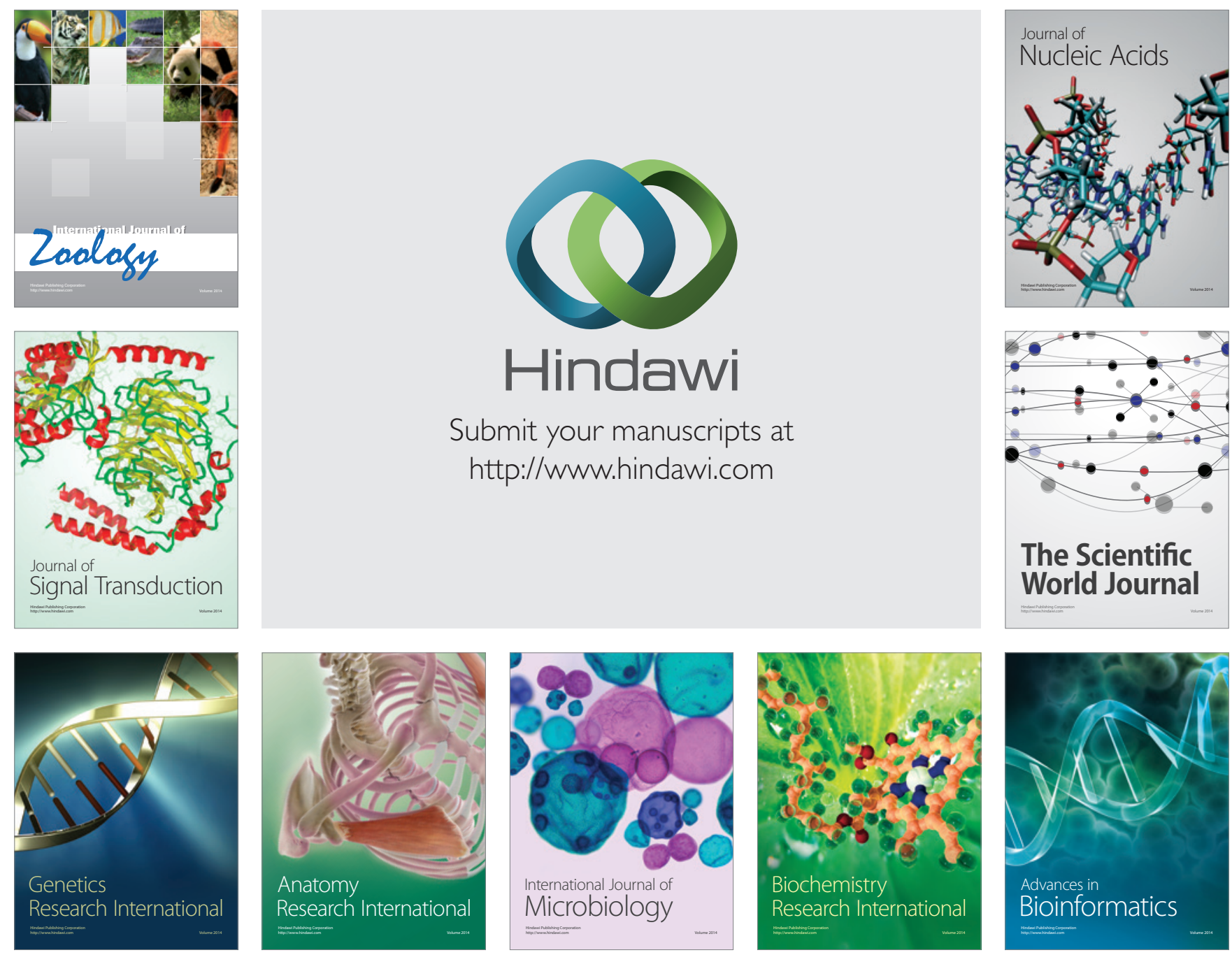

The Scientific World Journal
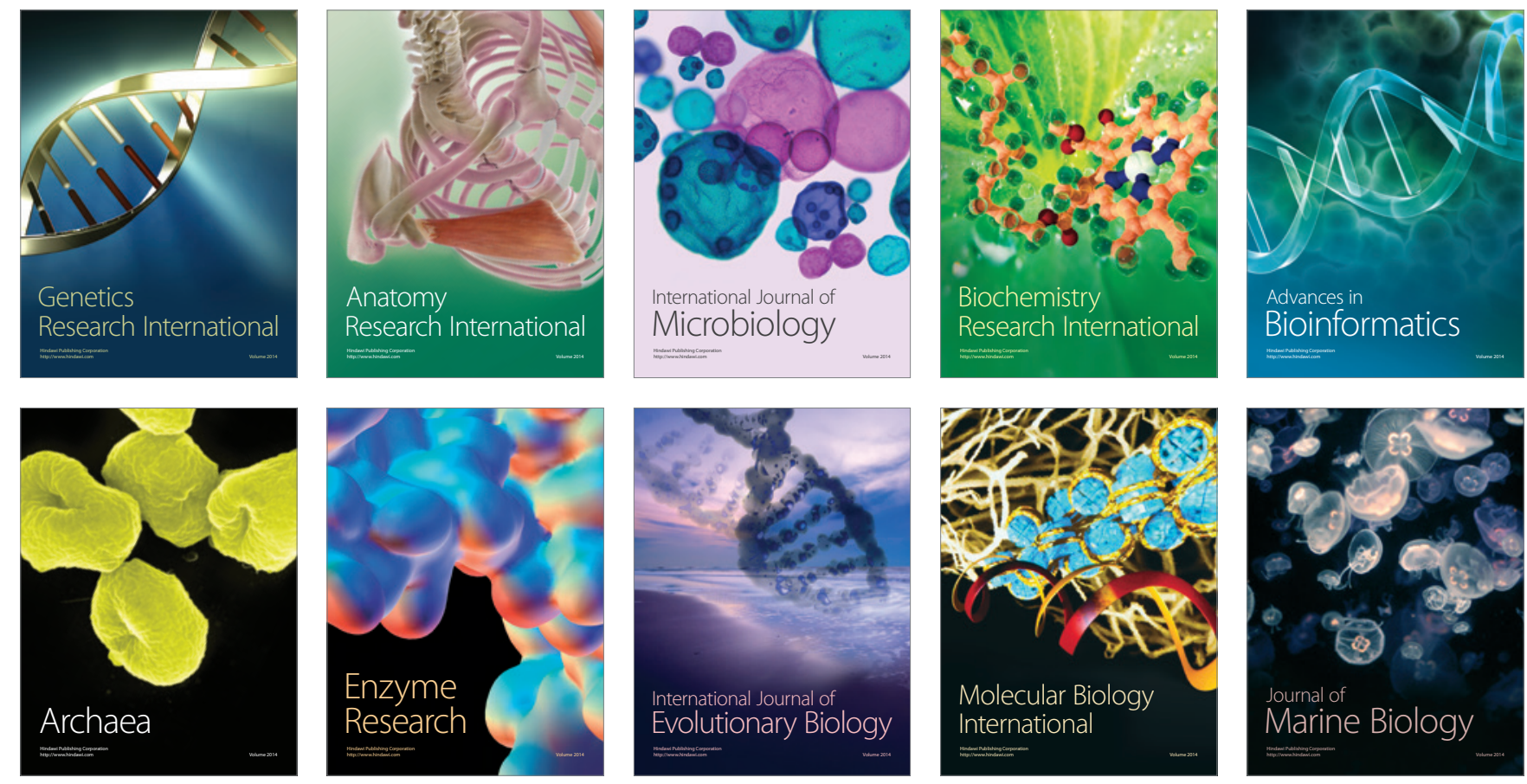